\title{
FORWARD CHAINING DALAM DIAGNOSIS PENYAKIT TUMBUHAN ALLIUM CEPA VAR AGGREGATUM
}

\author{
Dine Tiara Kusuma ${ }^{1)}$, Sely Karmila ${ }^{2)}$, Tiara Amalia Nova ${ }^{3)}$ \\ Jurusan Teknik Informatika, Sekolah Tinggi Teknik PLN \\ Email : dinetiara@sttpln.ac.id
}

\begin{abstract}
The agriculture department of Solok West Sumatra district especially Agricultural Extension Agency (BPP) of Lembang Jaya Sub-district, has decreased the productivity of onion every year. This plant has decreased because it often attacked by pests or diseases, and lack of knowledge about the symptoms of onion's pests or diseases. To fix this problem, made an application to facilitate the farmers, to know the type of pest or disease from symptoms on the onion and solution of each type of diseases. The method used is Forward Chaining. Forward Chaining Method is collection of data from each symptom that appear on the Allium Cepa Var Aggregatum. Then, made a decision to get the results about the solution and type of disease on the Allium Cepa Var Aggregatum. The results of this study is to show the type of disease and solution that has been detected based on symptoms on the Allium Cepa Var Aggregatum.
\end{abstract}

Keywords: Diagnosis, Symptoms, Forward Chaining method, Allium Cepa Var Aggregatum

\begin{abstract}
ABSTRAK
Dinas Pertanian kabupaten Solok Sumatera Utara Khusunya Balai Penyuluhan Pertanian (BPP) Kecamatan Lembang Jaya mengalami penurunan produktivitas pada tumbuhan jenis Allium Cepa Var Aggregatum setiap tahunnya. Jenis Tanaman ini mengalami penurunan prokdutivitas kerena sering diserang oleh hama dan penyakit. Hal ini disebebkan karena kurangnya pengetahuan petani mengenai gejala-gejala pada setiap hama dan penyakit pada jeis tumbuhan Allium Cepa Var Aggregatum. Untuk mengatasi masalah ini, dibuat sebuah sistem pakar yang dapat membantu petani memudahkan mengetahui jenis hama atau penyakit dari gejala-gejala yang ada pada tumbuhan Allium Cepa Var Aggregatum beserta solusi dari setiap jenis penyakitnya. Metode yang digunakan yaitu Forward Chaining. Metode Forward Chaining berupa pengumpulan fakta dari setiap gejala-gejala yang ada pada bawang merah, kemudian dibuatkan suatu pohon keputusan untuk mendapatkan hasil mengenai solusi dan jenis penyakit yang ada pada tumbuhan Allium Cepa Var Aggregatum. Hasil dari penelitian ini yaitu menampilkan jenis penyakit dan solusi dari setiap jenis penyakit pada tumbuhan Allium Cepa Var Aggregatum yang terdeteksi berdasarkan gejala-gejala yang terjadi.
\end{abstract}

Kata Kunci: Diagnosa, Gejala, Allium Cepa Var Aggregatum, Forward Chaining 


\section{PENDAHULUAN}

Indonesia terkenal dengan banyaknya rempah-rempah dan jenis sayuran yang mempunyai berbagai macam dan manfaat. Sebagian besar pekerjaan penduduk di Indonesia mayoritas petani begitu pula di daerah Padang Sumatera Barat khususnya daerah Kecamatan Lembang Jaya yang sebagian besar bekerja sebagai petani dan merupakan sumber pemasukan bagi masyarakat .

Kecamatan Lembang Jaya dengan luas wilayah kurang lebih 9.990 Ha mempunyai potensi pertanian yang sangat menjanjikan karena adanya tanaman pangan, perikanan, holtikultura, perkebunan, peternakan, tanah yang subur, sawah yang terhampar luas, air yang melimpah, iklim yang temurun meliputi tanaman jagung, cabai, ubi jalar, ubi kayu, kentang, buncis, tomat, bawang merah, bawang putih .

Berdasarkan buku laporan tahunan di Balai Penyuluhan Pertanian Kec.Lembang Jaya Khususnya tanaman Allium Cepa Var Aggregatum dengan luas tanam 447 Ha menghasilkan potensi panen sebesar $15 \mathrm{Ton} / \mathrm{Ha}$. Namun berdasarkan data yang dikeluarkan oleh Balai Penyuluhan Pertanian Kecamatan Lembang Jaya, hasil panen dengan potensi panen yang diharapkan berbeda cukup jauh, yaitu panen petani hanya 10,29 Ton/Ha jadi terdapat perbedaan 4,71 Ton/Ha, hal ini disebabkan oleh beberapa faktor, salah satunya penanggulangan terhadap hama dan penyakit yang menyerang jenis tanaman ini.

Allium Cepa Var Aggregatum adalah salah jenis tumbuhan bawang yang merupakan hasil pertanian daerah Lembang Jaya, Kabupaten Solok, Sumatera Barat, Indonesia. Berdasarkan selisih antara potensi panen petani dengan panen yang sesungguhnya sebesar $4.71 \mathrm{Ton} / \mathrm{Ha}$, dapat berdampak kerugian terhadap petani-petani tersebut. Kerugian ini tidak bisa dibiarkan terus menerus terjadi, karena akan berdampak terhadap pertumbuhan ekonomi wilayah tersebut sehingga perlu di cari solusi nya.

Salah satu solusi yang dtawarkan adalah dengan dilakukannya penyuluhan terhadap para petani petani tumbuhan Allium Cepa Var Aggregatum diwilayah Lembang Jaya. Penyuluhan dilakukan oleh Tim dari Balai Penyuluhan Pertanian Kecamatan Lembang Jaya, Solok. Jumlah petani yang cukup banyak dibandingkan dengan jumlah penyuluh yang sangat minim di wilayah ini serta jarak tempuh antara Balai Penyuluhan dan pemukiman petani yang cukup jauh membuat Ketua Balai Penyuluhan Pertanian Lembang Jaya harus melakukan pembagian jadwal terhadap Tim Penyuluh dari Balai Penyuluhan Pertanian Lembang Jaya ini. Namun hal ini bukanlah solusi yang cukup optimal, karena petani tidak hanya bisa menunggu penyuluhan yang diberikan oleh Tim Penyuluh datang baru dapat melakukan tindakan terhadap penyakit tumbuhan Allium Cepa Var Aggregatu muncul. Tindakan terhadap penyakit pada tumbuhan ini harus ditangani sesegera mungkin sebelum tumbuhan tersebut mati dan berdampak pada kerugian yang besar bagi para petani.

Sistem pakar (expert system) adalah sistem yang berusaha mengadopsi pengetahuan manusia ke komputer, agar komputer dapat menyelesaikan masalah seperti yang biasa dilakukan oleh para ahli, dan sistem pakar yang baik dirancang agar dapat menyelesaikan suatu permasalahan tertentu dengan meniru kerja dari para ahli.

Tidak banyak ahli yang paham mengenai penyakit pada tumbuhan Allium Cepa Var Aggregatu, dalam mendiagnosa suatu penyakit yang menyerangnya tentunya harus disertakan gejala-gejala yang terjadi terhadap penyakit tersebut. Beberapa gejala yang dapat muncul bersamaan tentunya akan menyimpulkan sebuah diagnosa sebuah penyakit dan harus diberikan solusi terhadap permasalahan penyakit yang muncul tersebut agar dapat ditanggulagi secara optimal.

Salah satu metode sistem pakar yang dapat bekerja berdasarkan gejala-gejala yang muncul dari sebuah kejadian adalah metode Forward Chaining. Forward Chaining adalah suatu metode pengambilan keputusan yang umum digunakan dalam sistem pakar. Proses pencarian dengan metode Forward Chaining berangkat dari kiri ke kanan, yaitu dari premis menuju kepada kesimpulan akhir, metode ini sering disebut data driven yaitu pencarian dikendalikan oleh data yang diberikan.

Berdasarkan permasalahan yang telah dikemukakan diatas, dibutuhkan sebuah sistem yang dapat mengatasi hal tersebut. Metode yang akan digunakan pada penelitian ini adalah metode 
Forward Chaining dimana pengetahuan dari pakar dalam hal ini yang akan berperan adalah Penyuluh dari Balai Penyuluhan Pertanian Kecamatan Lembang Jaya, Solok akan direpresentasikan dalam sebuah sistem aplikasi yang dapat dipergunakan oleh para petani, sehingga petani dapat mengetahui berbagai macam jenis penyakit pada tanaman Allium Cepa Var Aggregatu serta solusi penanganannya dimanapun dan kapanpun tanpa harus menunggu jadwal kedatangan tim penyuluh dari Balai Penyuluhan. Sehingga pada penelitian ini akan membahas topik tentang Forward Chaining dalam Diagnosis Penyakit Tumbuhan Allium Cepa Var Aggregatum agar dapat membantu petani dan tumbuhan Allium Cepa Var Aggregatu dalam mengidentifikasi atau mendiagnosa hama dan penyakit pada tumbuhan Allium Cepa Var Aggregatu sehingga dapat membantu mengurangi atau memperkecil resiko kerusakan tanaman.

\section{LANDASAN TEORI}

\section{Sistem Pakar}

Secara umum, sistem pakar (expert system) adalah sistem yang berusaha mengadopsi pengetahuan manusia ke komputer agar komputer dapat menyelesaikan masalah seperti yang dilakukan para ahli. Sistem pakar yang baik dirancang agar dapat menyelesaikan masalah tertentu dengan meniru cara kerja dari para ahli. Dengan sistem pakar ini orang awampun dapat menyelesaikan masalah yang cukup rumit yang sebenarnya hanya dapat diselesaikan dengan bantuan seorang ahli. Bagi para ahli sistem pakar ini juga dapat membantunya sebagai asisten yang sangat berpengalaman (Arhami, 2004)

Ada beberapa pengertian sistem pakar oleh beberapa orang ahli, yaitu :

a. Menurut Durkin (1994) : Sistem pakar adalah suatu program komputer yang dirancang untuk memodelkan kemampuan penyelesaian masalah yang dilakukan oleh seorang pakar.

b. Menurut Ignizio (1991): Sistem pakar adalah suatu model dan prosedur yang berkaitan, dalam suatu domain tertentu, yang mana tingkat keahliannya dapat dibandingkan dengan keahlian seorang pakar.

c. Menurut Arhami (2004) : Sistem pakar adalah salah satu cabang dari AI yang membuat penggunaan secara luas knowledge yang khusus untuk menyelesaikan masalah tingkat manusia yang pakar.

Kesimpulanya, seorang pakar adalah orang yang mempunyai keahlian dalam bidang tertentu, yaitu pakar yang mempunyai kemampuan khusus dan pengetahuan yang tidak semua orang mengetahui atau mampu dalam bidang yang dimilikinya. Sistem pakar adalah pengimplementasian keahlian, kemampuan, dan pengetehuan pakar tersebut kedalam suatu sistem komputer dengan tujuan dapat membantu penyelesaian suatu masalah yang membutuhkan pengetahuan seorang pakar.

\section{Metode Forward Chaining}

Melakukan inferensi membutuhkan proses pengujian kaidah-kaidah dalam urutan tertentu untuk mencari yang sesuai dengan kondisi awal atau kondisi yang berjalan, yang sudah menjadi masukan dalam basis data. Mesin inferensi mencari kaidah-kaidahdalam basis pengetahuan yang premisnya sesuai dengan fakta-fakta tersebut, kemudian dari aturan-aturan tersebut diperoleh suatu kesimpulan. Perunutan adalah proses pencocokan fakta, pernyataan atau kondisi berjalan yang tersimpan pada basis pengetahuan maupun pada memori kerja dengan kondisi yang dinyatakan pada premis atau bagian kondisi pada kaidah. Metode forward chaining merupakan proses perunutan dimulai denganmenampilkan kumpulan data atau fakta yang menyakinkan menuju konklusi akhir (Kurniawan, 2014). 


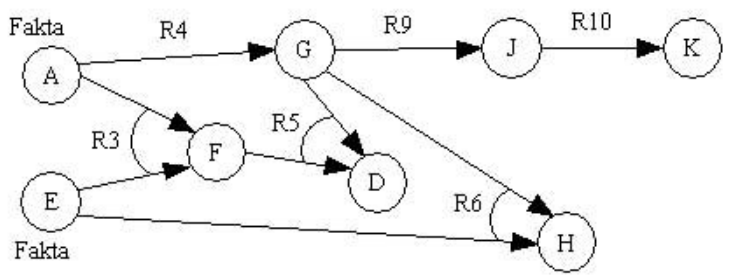

Gambar 1 Metode Forward Chaining

Metode Forward Chaining adalah suatu metode pengambilan keputusan yang umum digunakan dalam sistem pakar. Proses pencarian dengan metode Forward Chaining berangkat dari kiri ke kanan, yaitu dari premis menuju kepada kesimpulan akhir, metode ini sering disebut data driven yaitu pencarian dikendalikan oleh data yang diberikan. Aktivitas sistem dilakukan berdasarkan siklus mengenal-beraksi. Mula-mula, sistem mencari semua aturan yang kondisinya terdapat di memori kerja, kemudian memilih salah satunya dan menjalankan aksi yang bersesuaian dengan aturan tersebut. Pemilihan aturan yang akan dijalankan berdasarkan strategi tetap yang disebut strategi penyelesain konflik. Aksi tersebut menghasilkan memori kerja baru dan siklus diulangi lagi sampai tidak ada aturan yang dapat dipicu, atau tujuan yang dikehendaki sudah terpenuhi.

Forward Chaining digunakan jika :

a. Banyak aturan berbeda yang dapat memberikan kesimpulan yang sama.

b. Banyak cara untuk mendapatkan sedikit konklusi.

c. Benar-benar sudah mendapatkan pelbagai fakta, dan ingin mendapatkan konklusi dari faktafakta tersebut.

Adapun tipe sistem yang dapat menggunakan teknik pelacakan forward chaining, yakni :

a. Sistem yang direpresentasikan dengan satu atau beberapa kondisi.

b. Untuk setiap kondisi, sistem mencari rule-rule dalam knowledge base untuk rule-rule yang berkorespondensi dengan kondisi dalam bagian if.

c. Setiap rule dapat menghasilkan kondisi baru dari konklusi yang diminta pada bagian then. Kondisi baru ini dapat ditambahkan ke kondisi lain yang sudah ada.

d. Setiap kondisi yang ditambahkan ke sistem akan diproses. Jika ditemui suatu kondisi, sistem akan kembali ke langkah 2 dan mencari rule-rule dalam knowledge base kembali. Jika tidak ada konklusi baru, sesi ini berakhir.

\section{METODOLOGI PENELITIAN}

Tahapan pengembangan sistem pakar yang digunakan pada penelitian ini sebagai berikut :

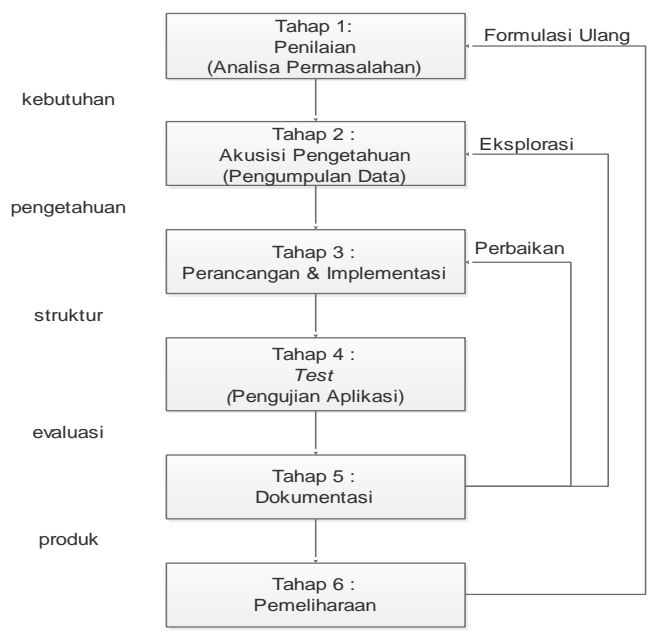

Gambar 2 Tahapan Pengembangan Sistem 
1. Penilaian (Assessement)

Merupakan proses untuk menentukan kelayakan dan justifikasi atas permasalahan yang akan diambil. Setelah proyek pengembangan dianggap layak dan sesuai dengan tujuan, maka selanjutnya ditentukan fitur-fitur penting dan ruang lingkup proyek serta sumber daya yang dibutuhkan. Sumber pengetahuan yang diperlukan diidentifikasi dan ditentukan persyaratanpersyaratan proyek.

2. Akuisisi Pengetahuan

Merupakan proses untuk mendapatkan pengetahuan tentang permasalahan yang akan dibahas dan digunakan sebagai panduan dalam pengembangan. Pengetahuan ini digunakan untuk memberikan informasi tentang permasalahan yang menjadi bahan acuan dalam mendesain system pakar. Tahap ini meliputi studi dengan diadakannya pertemuan dengan pakar untuk membahas aspek dari permasalahan.

3. Perancangan (Design) dan Implementasi

Berdasarkan pengetahuan yang telah didapatkan dalam proses akuisisi pengetahuan, maka desain antarmuka maupun teknik penyelesaian masalah dapat diimplementasikan kedalam system pakar. Dalam tahap desain ini, seluruh struktur dan organisasi dari pengetahuan harus ditetapkan dan dapat direpresentasikan kedalam sistem. Pada tahap desain, sebuah sistem prototype di bangun. Tujuan dari pembangunan prototype tersebut adalah untuk memberikan pemahaman yang lebih baik atas masalah.

4. Pengujian

Tahap ini dimaksudkan untuk menguji apakah sistem pakar yang dibangun telah sesuai dengan tujuan pengembangan maupun kesesuaian kinerja sistem dengan metode penyelesaian masalah yang bersumber dari pengetahuan yang sudah didapkan. Apabila dalam tahap ini terdapat bagian yang harus dievaluasi maupun dimodifikasi maka hal tersebut harus segera dilakukan agar sistem pakar dapat berfungsi sebagaimana tujuan pengembangannya.

5. Dokumentasi

Tahap kelima akan dilakukan dokumentasi error code yang biasa muncul dalam suatu permasalahan software.

6. Pemeliharaan

Pada tahap pemeliharaan akan dilakukan tahap untuk kembali ke tahap-tahap sebelumnya guna memperbaiki sistem agar agar sistem yang di bangun tidak out-of-date, dan selalu melakukan iterasi untuk memenuhi kebutuhan informasi kepada pengguna (user).

\section{Alat dan Bahan}

1. Perangkat Keras

- 1 (satu) unit laptop dengan spesifikasi sebagai berikut :

○ Processor Intel(R) Core(TM) i5-2520M CPU @2.50GHz 2.50 GHZ

○ RAM berkapasitas $4.00 \mathrm{~GB}$

○ HDD 500GB

- $\quad$ Smartphone Xiomi Android versi 6.0

2. Perangkat Lunak (Software)

- Windows 10 64-bit pada laptop

- App Inventor

- Browser Google Chrome

- $\quad$ Microsoft Word 2013

- $\quad$ Edraw Max 7.9

\section{HASIL DAN ANALISA}

1. Hasil

a. Halaman pertanyaan gejala penyakit 
Halaman ini adalah halaman yang digunakan oleh pengguna dalam hal ini Petani untuk mendiagnosis jenis penyakit pada tumbuhan Allium Cepa Var Aggregatu.

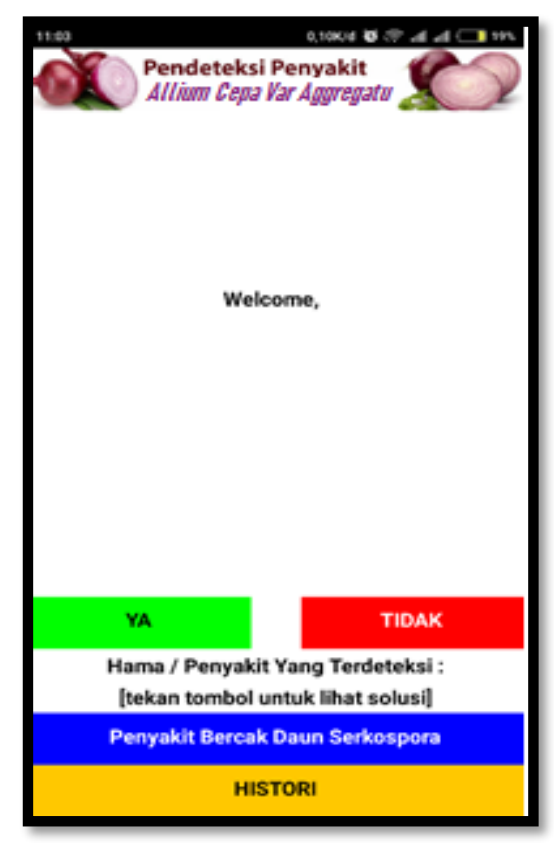

Gambar 3 Halaman Pertanyaan Gejala Penyakit

Pada halaman diatas Petani dapat menjawab gejala-gejala pada tanaman Allium Cepa Var Aggregatu yang terjadi. Ada 28 gejala penyakit yang dapat di jawab oleh Petani agar dapat mendiagnosis jenis penyakit yang terjadi pada tumbuhan Allium Cepa Var Aggregatu ini sehingga dapat diberikan solusi yang yang tepat.

b. Halaman hasil diagnosa penyakit dan solusi penanganan

Halaman ini adalah halaman yang menampilkan hasil diagnosa penyakit dan solusi penanganannya

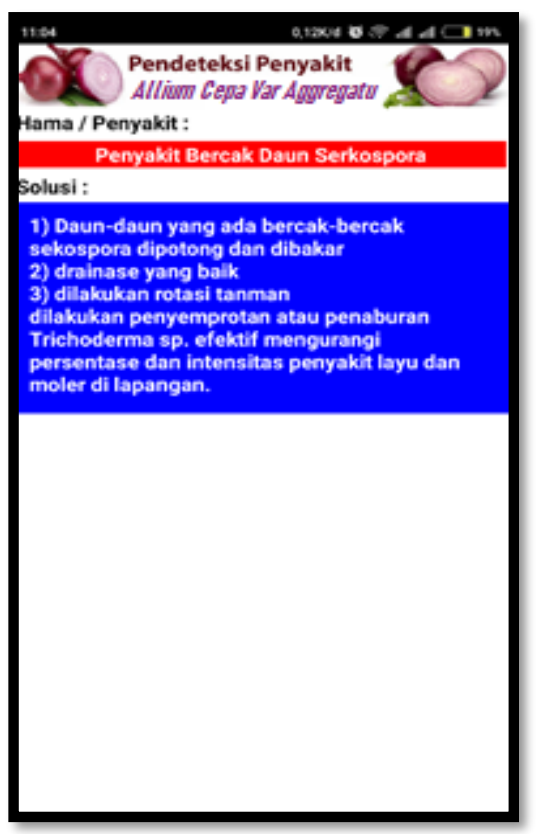

Gambar 4 Halaman Hasil Diagnosa Penyakit Dan Solusi Penanganan 
Pada halaman diatas petani dapat memeperoleh informasi mengenai diagnosis penyakit berdasarkan dari jawaban pertanyaan gejala-gejala yang terjadi pada tanaman tumbuhan Allium Cepa Var Aggregatu ini. Halaman ini juga disertai oleh solusi penanganannya.

\section{Analisa}

\section{a. Tabel Pengkodean Nama Penyakit}

\begin{tabular}{|c|l|}
\hline Kode & \multicolumn{1}{|c|}{ Nama Penyakit } \\
\hline P01 & Ulat Tanah(Agrotis Ipsilon) \\
\hline P02 & Lalat penggorok Daun(Liriomyza Chinensis) \\
\hline P03 & Ulat Daun \\
\hline P04 & Ulat grayak \\
\hline P05 & Thrips Tabaci \\
\hline P06 & Orong-orong Atau Anjing Tanah (Gryllotalpa Africana ) \\
\hline P07 & Hama Ngengat Daun \\
\hline P08 & Hama Orong-orong \\
\hline P09 & Penyakit Moler / Layu Fusarum (Twisting Disaesu) \\
\hline P10 & Penyakit Ngelumpruk / Leumpeuh (Stemphylium Leaf Blight) \\
\hline P11 & Penyakit Bercak Daun Serkospora \\
\hline P12 & Penyakit Bercak Hijau-hijau (Antraknose) \\
\hline P13 & Bercak Ungu \\
\hline P14 & Busuk Daun (Peronospora Destructor) \\
\hline P15 & Penyakit Mati Pucuk \\
\hline
\end{tabular}

\section{b. Tabel Pengkodean Gejala Penyakit}

\begin{tabular}{|c|l|}
\hline Kode & \multicolumn{1}{|c|}{ Pertanyaan } \\
\hline T1 & Apakah usia tanaman saat ini adalah 2-3 minggu ? \\
\hline T2 & Apakah akar tanaman rusak ? \\
\hline T3 & Apakah daun menjadi layu ? \\
\hline T4 & Apakah daun kering ? \\
\hline T5 & Apakah usia tanaman saat ini adalah 1-10 hari ? \\
\hline T6 & Apakah batang mengalami kerusakan ? \\
\hline T7 & Apakah terdapat bercak putih pada daun ? \\
\hline T8 & Apakah terjadi pembusukan pada daun / batang ? \\
\hline T9 & Apakah terbentuk massa jamur seperti beludru ? \\
\hline T10 & Apakah daun berwarna coklat ? \\
\hline T11 & Apakah daun berlubang ? \\
\hline T12 & Apakah ditemukan larva ? \\
\hline T13 & Apakah permukaan daun tembus cahaya ? \\
\hline T14 & Apakah ditemukan ulat pada daun? \\
\hline T15 & Apakah terdapat lubang pada umbi ? \\
\hline T16 & Apakah terjadi pembusukan pada umbi ? \\
\hline T17 & Apakah terdapat kappang hitam pada daun ? \\
\hline T18 & Apakah daun mulai menguning ? \\
\hline T19 & Apakah daun terpelintir? \\
\hline
\end{tabular}




\begin{tabular}{|l|l|} 
T20 & Apakah kelembaban udara tinggi ? \\
\hline T21 & Apakah ada bercak ungu / kelabu ? \\
\hline T22 & Apakah pada daun terdapat bercak berwarna hijau pucat ? \\
\hline T23 & Apakah ada gejala botak-botak pada tanaman ? \\
\hline T24 & Apakah daun menjadi belang-belang? \\
\hline T25 & Apakah terdapat cendawan berwarna putih ? \\
\hline T26 & Apakah daun berwarna kuning ? \\
\hline T27 & Apakah tinggi tanaman termasuk kerdil ? \\
\hline T28 & Apakah pada daun terdapat kotoran hama dan daun menjadi hitam ? \\
\hline
\end{tabular}

\section{c. Analisa mesin inferensi}

\section{Struktur Pohon Keputusan}

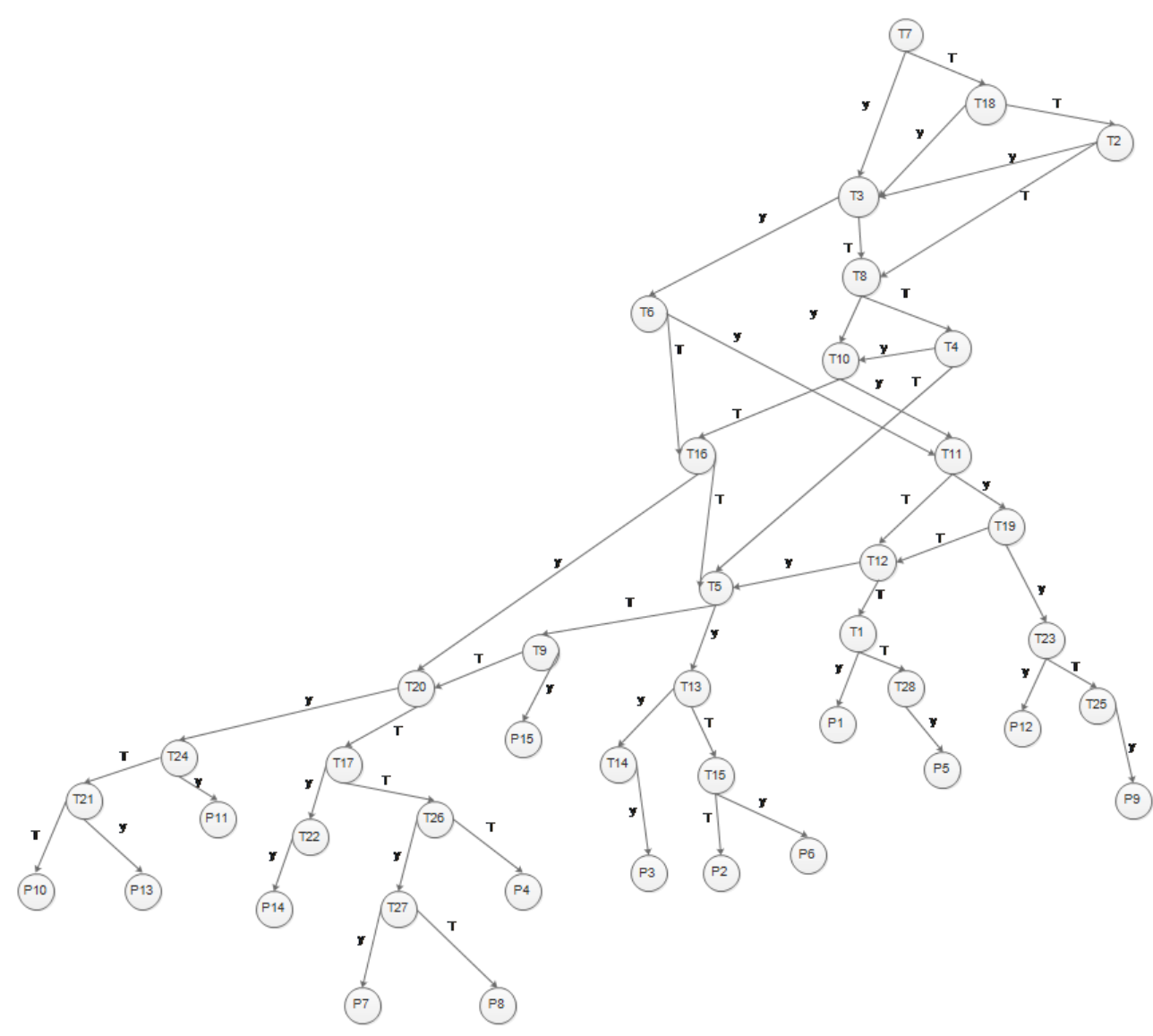

Gambar 5 Pohon Keputusan

Keterangan :

- T1-128 : Pertanyaan Gejala Penyakit

- P1-15 : Nama Penyakit

Selanjutnya untuk mesin Inferensi sebagai kontrol strategi digunakan untuk memilih rule yang akan digunakan. Mesin inferensi bekerja dalam sebuah looping, melakukan identifikasi dan mengeksekusi dengan kasus yang memiliki rule lebih dari satu, sehingga terbagi menjadi beberapa alokasi penyimpanan mulai dari untuk menyimpan fakta Ya, fakta Tidak, fakta Solusi, fakta rule, fakta rule yang sudah 
ditanyakan serta beberapa fakta lainnya. Berikut merupakan tabel aturan / rule terhadap pertanyaan gejala penyakit dan jawaban nama penyakit.

Tabel 1 Tabel Aturan Produksi

\begin{tabular}{|c|l|}
\hline NO & \multicolumn{1}{|c|}{ ATURAN } \\
\hline 1 & IF T1 AND (T2,T3,T6) THEN P1 \\
\hline 2 & IF T4 AND(T5,T7,T10,T12) THEN P2 \\
\hline 3 & IF T5 AND (T7,T13,T14) THEN P3 \\
\hline 4 & IF T3 AND (T6,T7,T11,T12) THEN P4 \\
\hline 5 & IF T7 AND (T8,T10,T28) THEN P5 \\
\hline 6 & IF T2 AND (T3,T5,T15) THEN P6 \\
\hline 7 & IF T2 AND (T3,T11,T26,T27) THEN P7 \\
\hline 8 & IF T2 AND (T3,T4, T10,T26) THEM P8 \\
\hline 9 & IF T3 AND (T16,T18,T19,T25) THEN P9 \\
\hline 10 & IF T7 AND (T20) THEN P10 \\
\hline 11 & IF T7 AND (T20,T24) THEN P11 \\
\hline 12 & IF T7 AND (T8,T10,T11,T19,T23) THEN P12 \\
\hline 13 & IF T4 AND (T7,T8,T16,T20,T21) THEN P13 \\
\hline 14 & IF T17 AND (T18,T22) THEN P 14 \\
\hline 15 & IF T8 AND T9 THEN P15 \\
\hline
\end{tabular}

\section{d. Hasil Diagnosis Penyakit}

- Hasil Diagnosis Penyakit Ulat Tanah (Agrotis Ipsilon)

Aturan produksi dari Ulat Tanah terdapat pada point 1, atau dalam pemilihan jawaban pada pertanyaan aplikasi gejala yang dijawab dengan status "Ya" pada aplikasi adalah sebagai berikut:

Tabel 2 Hasil Diagnosis Penyakit Ulat Tanah

\begin{tabular}{|c|l|}
\hline Kode Gejala & \multicolumn{1}{c|}{ Pertanyaan } \\
\hline G1 & Usia tanaman saat ini adalah 2-3 minggu \\
\hline G2 & Akar tanaman rusak \\
\hline G4 & Daun kering \\
\hline G6 & Batang mengalami kerusakan \\
\hline
\end{tabular}

- $\quad$ Hasil Diagnosis Lalat penggorok (Liriomyza Chinensis

Aturan produksi dari penyakit tungau terdapat pada point 2, atau dalam pemilihan jawaban pada pertanyaan aplikasi gejala yang dijawab dengan status "Ya" pada aplikasi adalah sebagai berikut:

Tabel 3 Hasil Diagnosis Lalat Penggorok (Liriomyza Chinensis)

\begin{tabular}{|c|l|}
\hline Kode Gejala & \multicolumn{1}{|c|}{ Pertanyaan } \\
\hline G4 & Daun kering \\
\hline G5 & Usia tanaman saat ini adalah 1-10 hari \\
\hline G7 & Terdapat bercak putih pada daun \\
\hline G10 & Daun berwarna coklat \\
\hline G12 & Ditemukan larva \\
\hline
\end{tabular}


- Hasil Diagnosis Ulat Daun

Aturan produksi dari penyakit hawar/antroksa sulur terdapat pada point 3, atau dalam pemilihan jawaban pada pertanyaan aplikasi gejala yang dijawab dengan status "Ya" pada aplikasi adalah sebagai berikut:

Tabel 4 Hasil Diagnosis Ulat Daun

\begin{tabular}{|c|l|}
\hline Kode Gejala & \multicolumn{1}{|c|}{ Pertanyaan } \\
\hline G5 & Usia tanaman saat ini adalah 1-10 hari \\
\hline G7 & Terdapat bercak putih pada daun \\
\hline G13 & Permukaan daun tembus cahaya \\
\hline G14 & Ditemukan ulat pada daun \\
\hline
\end{tabular}

- Hasil Diagnosis Penyakit Ulat Grayak

Aturan produksi dari penyakit kuning sulur terdapat pada point 4 , atau dalam pemilihan jawaban pada pertanyaan aplikasi gejala yang dijawab dengan status "Ya" pada aplikasi adalah sebagai berikut:

Tabel 5 Hasil Diagnosis Penyakit Ulat Grayak

\begin{tabular}{|l|l|}
\hline Kode Gejala & \multicolumn{1}{|c|}{ Pertanyaan } \\
\hline G3 & Daun menjadi layu \\
\hline G6 & Batang mengalami kerusakan \\
\hline G7 & Terdapat bercak putih pada daun \\
\hline G11 & Daun berlubang \\
\hline G12 & Ditemukan larva \\
\hline
\end{tabular}

- $\quad$ Hasil Diagnosis Penyakit Thrips Tabaci

Aturan produksi dari penyakit busuk bakteri terdapat pada point 5, atau dalam pemilihan jawaban pada pertanyaan aplikasi gejala yang dijawab dengan status "Ya" pada aplikasi adalah sebagai berikut:

Tabel 6 Hasil Diagnosis Penyakit Thrips Tabaci

\begin{tabular}{|c|l|}
\hline Kode Gejala & \multicolumn{1}{|c|}{ Pertanyaan } \\
\hline G7 & Terdapat bercak putih pada daun \\
\hline G8 & Terjadi pembusukan pada daun / batang \\
\hline G10 & Daun berwarna coklat \\
\hline G28 & Pada daun terdapat kotoran hama dan daun menjadi hitam \\
\hline
\end{tabular}

- Hasil Diagnosis Penyakit Orong-orong Atau Anjing Tanah (Gryllotalpa Africana)

Aturan produksi dari penyakit fusarium terdapat pada point 6 , atau dalam pemilihan jawaban pada pertanyaan aplikasi gejala yang dijawab dengan status "Ya" pada aplikasi adalah sebagai berikut: 
Tabel 7 Hasil Diagnosis Penyakit Orong-Orong Atau Anjing Tanah

\begin{tabular}{|l|l|}
\hline Kode Gejala & \multicolumn{1}{|c|}{ Pertanyaan } \\
\hline G2 & Akar tanaman rusak \\
\hline G3 & Daun menjadi layu \\
\hline G5 & Usia tanaman saat ini adalah 1-10 hari \\
\hline G15 & Terdapat lubang pada umbi \\
\hline
\end{tabular}

- Hasil Diagnosi Hama Ngengat Daun Bawang Merah

Aturan produksi dari penyakit hawar/antroksa sulur terdapat pada point 7 , atau dalam pemilihan jawaban pada pertanyaan aplikasi gejala yang dijawab dengan status "Ya" pada aplikasi adalah sebagai berikut:

Tabel 8 Hasil Diagnosi Hama Ngengat Daun Bawang Merah

\begin{tabular}{|l|l|}
\hline Kode Gejala & \multicolumn{1}{|c|}{ Pertanyaan } \\
\hline G2 & Akar tanaman rusak \\
\hline G3 & Daun menjadi layu \\
\hline G11 & Daun berlubang \\
\hline G26 & Daun berwarna kuning \\
\hline G27 & Tinggi tanaman termasuk kerdil \\
\hline
\end{tabular}

- Hasil Diagnosis Penyakit Hama Orong-orong Bawang Merah

Aturan produksi dari penyakit hawar/antroksa sulur terdapat pada point 8 , atau dalam pemilihan jawaban pada pertanyaan aplikasi gejala yang dijawab dengan status "Ya" pada aplikasi adalah sebagai berikut:

Tabel 9 Hasil Diagnosis Penyakit Hama Orong-Orong

\begin{tabular}{|l|l|}
\hline Kode Gejala & \\
\hline G2 & Akar tanaman rusak \\
\hline G3 & Daun menjadi layu \\
\hline G4 & Daun kering \\
\hline G10 & Daun berwarna coklat \\
\hline G26 & Daun berwarna kuning \\
\hline
\end{tabular}

- $\quad$ Hasil Diagnosis Penyakit Moler / Layu Fusarum (Twisting Disaesu)

Aturan produksi dari penyakit hawar/antroksa sulur terdapat pada point 9, atau dalam pemilihan jawaban pada pertanyaan aplikasi gejala yang dijawab dengan status "Ya" pada aplikasi adalah sebagai berikut:

Tabel 10 Hasil Diagnosis Penyakit Moler

\begin{tabular}{|c|l|}
\hline Kode Gejala & \multicolumn{1}{|c|}{ Pertanyaan } \\
\hline G9 & Terbentuk massa jamur seperti beludru \\
\hline G16 & terjadi pembusukan pada umbi \\
\hline G18 & daun mulai menguning \\
\hline G19 & daun terpelintir \\
\hline G25 & terdapat cendawan berwarna putih \\
\hline
\end{tabular}


- $\quad$ Hasil Diagnosis Penyakit Ngelumpruk / Leumpeuh (Stemphylium Leaf Blight) Aturan produksi dari penyakit hawar/antroksa sulur terdapat pada point 10, atau dalam pemilihan jawaban pada pertanyaan aplikasi gejala yang dijawab dengan status "Ya" pada aplikasi adalah sebagai berikut:

Tabel 11 Hasil Diagnosis Penyakit Ngelumpruk

\begin{tabular}{|c|l|}
\hline Kode Gejala & \multicolumn{1}{|c|}{ Pertanyaan } \\
\hline G7 & Terdapat bercak putih pada daun \\
\hline G20 & Kelembaban udara tinggi \\
\hline
\end{tabular}

- $\quad$ Hasil Diagnosis Penyakit Penyakit Bercak Daun Serkospora

Aturan produksi dari penyakit hawar/antroksa sulur terdapat pada point 11, atau dalam pemilihan jawaban pada pertanyaan aplikasi gejala yang dijawab dengan status "Ya" pada aplikasi adalah sebagai berikut:

Tabel 12 Hasil Diagnosis Penyakit Bercak Daun Serkospora

\begin{tabular}{|c|l|}
\hline Kode Gejala & \multicolumn{1}{|c|}{ Pertanyaan } \\
\hline G11 & Daun berlubang \\
\hline G20 & Kelembaban udara tinggi \\
\hline G24 & Daun menjadi belang-belang \\
\hline
\end{tabular}

- $\quad$ Hasil Diagnosis Penyakit Bercak Hijau-hijau (Antraknose)

Aturan produksi dari penyakit hawar/antroksa sulur terdapat pada point 12, atau dalam pemilihan jawaban pada pertanyaan aplikasi gejala yang dijawab dengan status "Ya" pada aplikasi adalah sebagai berikut:

Tabel 13 Hasil Diagnosis Penyakit Bercak Hijau-Hijau (Antraknose)

\begin{tabular}{|c|l|}
\hline Kode Gejala & \multicolumn{1}{|c|}{ Pertanyaan } \\
\hline G7 & Terdapat bercak putih pada daun \\
\hline G8 & Terjadi pembusukan pada daun / batang \\
\hline G10 & Daun berwarna coklat \\
\hline G11 & Daun berlubang \\
\hline G19 & Daun terpelintir \\
\hline G23 & Ada gejala botak-botak pada tanaman \\
\hline
\end{tabular}

- $\quad$ Hasil Diagnosis Penyakit Bercak Ungu

Aturan produksi dari penyakit hawar/antroksa sulur terdapat pada point 13, atau dalam pemilihan jawaban pada pertanyaan aplikasi gejala yang dijawab dengan status "Ya" pada aplikasi adalah sebagai berikut:

Tabel 14 Hasil Diagnosis Penyakit Bercak Ungu

\begin{tabular}{|c|l|}
\hline Kode Gejala & \multicolumn{1}{|c|}{ Pertanyaan } \\
\hline G4 & Daun kering \\
\hline G7 & Terdapat bercak putih pada daun \\
\hline G8 & terjadi pembusukan pada daun / batang \\
\hline G16 & terjadi pembusukan pada umbi \\
\hline G20 & kelembaban udara tinggi \\
\hline G21 & ada bercak ungu / kelabu \\
\hline
\end{tabular}


- $\quad$ Hasil Diagnosis Penyakit Busuk Daun (Peronospora Destructor)

Aturan produksi dari penyakit hawar/antroksa sulur terdapat pada point 14, atau dalam pemilihan jawaban pada pertanyaan aplikasi gejala yang dijawab dengan status "Ya" pada aplikasi adalah sebagai berikut:

Tabel 15 Hasil Diagnosis Penyakit Busuk Daun

\begin{tabular}{|c|l|}
\hline Kode Gejala & \multicolumn{1}{|c|}{ Pertanyaan } \\
\hline G17 & Terdapat kappang hitam pada daun \\
\hline G18 & Daun mulai menguning \\
\hline G22 & Pada daun terdapat bercak berwarna hijau pucat \\
\hline
\end{tabular}

- $\quad$ Hasil Diagnosis Penyakit Mati Pucuk

Aturan produksi dari penyakit hawar/antroksa sulur terdapat pada point 15 , atau dalam pemilihan jawaban pada pertanyaan aplikasi gejala yang dijawab dengan status "Ya" pada aplikasi adalah sebagai berikut:

Tabel 16 Hasil Diagnosis Penyakit Mati Pucuk

\begin{tabular}{|l|l|}
\hline Kode Gejala & \multicolumn{1}{c|}{ Pertanyaan } \\
\hline G8 & Terjadi pembusukan pada daun / batang \\
\hline G9 & Terbentuk massa jamur seperti beludru \\
\hline
\end{tabular}

\section{KESIMPULAN DAN SARAN}

\section{a. Kesimpulan}

Metode Forward Chaining yang digunakan dalam diagnosa penyakit pada tumbuhan Allium Cepa Var Aggregatum dapat diterapkan dengan menggunakan variabel gejala-gejala penyakit yang ada, sehingga akan menghasilkan diagnosa suat penyakit pada tumbuhan Allium Cepa Var Aggregatum beserta solusi yang ditawarkan, tergantung basis pengetahuan yang di input di dalam sistem.

\section{b. Saran}

Berdasarkan ujicoba yang telah dilakukan pada umumnya hasil yang diharapkan telah sesuai namun disarankan untuk penelitian selanjutnya dapat diusulkan terdapat fitur komunikasi antar petani dan penyuluh pada sistem.

\section{DAFTAR PUSTAKA}

Aprilia Sulistyohati, T. H. (2008). APLIKASI SISTEM PAKAR DIAGNOSA PENYAKIT GINJAL DENGAN. jurnal informatika, 1-5.

Arhami, M. (2004). Konsep Dasar Sistem Pakar. Yogyakarta: Andi.

B.Herawan Heriyadi, S. M. (2016). Sistem Pakar. Yogyakarta: Deepublish.

Deffy Susanti, S. (2017). PERANCANGAN SISTEM PAKAR DIAGNOSA PENYAKIT TANAMAN MANGGA DENGAN ALGORITMA DEPTH FIRST SEARCH BERBASIS MOBILE. Prosiding SINTAK, 24-32.

Durkin, J. (1994). Expert Systems Design and Development. New Jersey: Prentice Hall International Inc. 
Indah Puji Astuti1, I. H. (2016). RANCANG BANGUN SISTEM PAKAR PENANGGULANGAN PENYAKIT KEDELAI Design of an Expert System for Controlling Soybean Diseases. 117130.

KOSASI, S. (2014). SISTEM PAKAR DIAGNOSA PENYAKIT IKAN. Techsi, 37-50.

Latif, A. (2015). APLIKASI SISTEM PAKAR DETEKSI KERUSAKAN MOTOR MATIC MENGGUNAKAN METODE FOWARD CHAINING. Jurnal Ilmiah Mustek Anim, 254-262.

Muhammad Eka, N. A. (2017). SISTEM PAKAR IDENTIFIKASI DEFISIENSI UNSUR HARA PADA TANAMAN KOPI MENGGUNAKAN METODE CERTAINTY FACTOR BERBASIS WEB. Jurnal Sains Komputer \& Informatika, 223-236.

Novi Mega Shilvia1, S. R. (2016). PENGEMBANGAN SISTEM PAKAR DIAGNOSA AWAL PENYAKIT DALAM INTERNIS BERBASIS ANDROID. jurnal Algoritma , 356-366.

Pohan, H. I., \& Bahri , K. S. (1997). Pengantar Perancangan Sistem. PT.Gelora Aksara Pratama .

Rosnelly, R. (2012). Sistem Pakar:Konsep dan Teori. Yogyakarta: Andi.

Sutojo, t., mulyanto, e., \& suhartono, v. (2011). Kecerdasan buatan. Yogyakarta: Andi Yogyakarta. T Sutojo, e. a. (2011). Kecerdasan Buatan. Yogyakarta: Andi.

Turban, E., \& Aronson, E. (2001). Decision Support System and Intelligence System. Sixth Edition. New Jersey: Pearson Education. 


\title{
PERANCANGAN APLIKASI JEJARING SOSIAL ALUMI PENCINTA APLIKSI BERBASIS ITC DENGAN ALGORITMA GRAPH BERBASIS WEB
}

\author{
Fitri Latifah', Imam Saefudin ${ }^{2}$ \\ Program Studi Komputerisasi Akutansi, AMIK BSI Jakarta ${ }^{1}$ \\ Program Studi Teknik Informatika, STMIK Nusa Mandiri Jakarta ${ }^{2}$ \\ fitri.flr@bsi.ac.id \\ imamsaefudin10@gmail.com
}

\begin{abstract}
ABSTRAK
Alumi adalah orang yeng telah tamat dari sekolah atau perguruan tinggi. Alumni STMIK Nusa Mandiri atau biasa disebut dengan IKANI memiliki peranan penting dalam menunjukkan pencitraan dan kualitas sebuah perguruan tinggi, karena wadah ikatan alumni itu bukan sekadar forum silaturahmi antar alumni saja, tetapi juga wadah untuk berdiskusi dan mengomunikasikan upaya dan usaha dalam memajukan perguruan tinggi. Dengan memanfaatkan fasilitas internet maka dibuat sebuah situs jejaring sosial untuk alumni STMIK Nusa Mandiri yang dapat mempermudah komunikasi antar para alumni. Komunikasi dengan menggunakan situs jejaring sosial dapat menumbuhkan rasa kebersamaan, keakraban dan keterikatan yang lebih kental jika dibandingkan dengan media komunikasi lain yang ada di Internet. Jejaring sosial yang dirancang bertujuan bukan hanya menghubungkan alumi dari STMIK Nusamandiri, khsusnya untuk Program Studi Teknik Informatika sebagai wadah bertukar informasi dan membentuk komunitas untuk mengembangka diri dengan tujuan memperkaya pengetahuan di bidang ITC dengan cara betujar informasi. Situs ini dibuat dengan memulai perancangan sistem terebih dahulu menggunakanan UML kemudian dilanjutkan dengan pembuatan user interface dan dengan menggunakan bahasa pemograman PHP dan MySQL sebagai manajemen basis data. Situs ini masih memiliki beberapa kekurangan baik dari segi fitur maupun keamanan.
\end{abstract}

Kata kunci : Jejaring Sosial, Alumni Teknik Informatika STMIK Nusa Mandiri, berbasis web, Berbasis ITC, bahasa pemrograman PHP

\begin{abstract}
Alumni is a person who finished their studi from colege or university. Alumni STMIK Nusa Mandiri or commonly referred to as IKANI has an important role in showing the imaging and quality of a university, because the alumni container is not just a forum of friendship between alumni, but also a container to counsel and communicate efforts and efforts in advancing university. By utilizing the internet facility then created a social networking site for alumni STMIK Nusa Mandiri which can facilitate communication between the alumni. Communicating using this site can make friendship and knowledge in teh ITC, become closer than other site which already axist in Internet. This site was created by starting the first system design using UML then continued with the creation of user interface and by using programming language PHP and MYSQL as database management. The site still has some disadvantages in terms of both features and security.
\end{abstract}

Keyword : social networking, Alumni Teknik Informatika STMIK Nusa Mandiri, web programming, ITC base, PHP Language 